\title{
The proper concentrations of dextrose and lidocaine in regenerative injection therapy: in vitro study
}

\author{
Min Seok Woo ${ }^{1}$, Jiyoung Park ${ }^{2}$, Seong-Ho Ok ${ }^{2,4}$, Miyeong Park ${ }^{2}$, Ju-Tae Sohn ${ }^{3,4}$, Man Seok Cho ${ }^{5}$, Il-Woo Shin ${ }^{3,4}$, \\ and Yeon A Kim ${ }^{2,4}$
}

'Department of Convergence Medical Science, Gyeongsang National University, Jinju, Korea

${ }^{2}$ Department of Anesthesiology and Pain Medicine, Gyeongsang National University Changwon Hospital, Changwon, Korea

${ }^{3}$ Department of Anesthesiology and Pain Medicine, Gyeongsang National University Hospital, Jinju, Korea

${ }^{4}$ Institute of Health Sciences, Gyeongsang National University College of Medicine, Jinju, Korea

${ }^{5}$ Department of Anesthesiology and Pain Medicine, Gyeongsang National University College of Medicine, Jinju, Korea

Received June 19, 2020

Revised September 18, 2020

Accepted October 7, 2020

Handling Editor: Jeong-II Choi

\section{Correspondence}

Yeon A Kim

Department of Anesthesiology and Pain Medicine, Gyeongsang National University Changwon Hospital, 11 Samjeongja-ro, Seongsan-gu, Changwon 51472, Korea

Tel: +82-55-533-0808

Fax: +82-55-214-3269

E-mail: keivin@naver.com

\section{II-Woo Shin}

Department of Anesthesiology and Pain Medicine, Gyeongsang National University Hospital, 79 Gangnam-ro, Jinju 52727, Korea

Tel: +82-55-750-8137

Fax: +82-55-750-8137

E-mail: ilwooshin@gnu.ac.kr

\section{Previous presentation at conference} This article was presented at the 1st International Congress on Spinal Pain in Gwangju, Korea, 2016.
Background: Prolotherapy is a proliferation therapy as an alternative medicine. A combination of dextrose solution and lidocaine is usually used in prolotherapy. The concentrations of dextrose and lidocaine used in the clinical field are very high (dextrose $10 \%-25 \%$, lidocaine $0.075 \%-1 \%$ ). Several studies show about $1 \%$ dextrose and more than $0.2 \%$ lidocaine induced cell death in various cell types. We investigated the effects of low concentrations of dextrose and lidocaine in fibroblasts and suggest the optimal range of concentrations of dextrose and lidocaine in prolotherapy. Methods: Various concentrations of dextrose and lidocaine were treated in $\mathrm{NIH}$ 3Т3. Viability was examined with trypan blue exclusion assay and 3-(4,5-dimethylthiazol-2-yl)-2,5-diphenyltetrazolium bromide assay. Migration assay was performed for measuring the motile activity. Extracellular signal-regulated kinase (Erk) activation and protein expression of collagen I and $\alpha$-smooth muscle actin ( $\alpha$-SMA) were determined with western blot analysis.

Results: The cell viability was decreased in concentrations of more than $5 \%$ dextrose and $0.1 \%$ lidocaine. However, in the concentrations $1 \%$ dextrose (D1) and $0.01 \%$ lidocaine (L0.01), fibroblasts proliferated mildly. The ability of migration in fibroblast was increased in the D1, L0.01, and D1 + L0.01 groups sequentially. D1 and L0.01 increased Erk activation and the expression of collagen I and $\alpha$-SMA and D1 + L0.01 further increased. The inhibition of Erk activation suppressed fibroblast proliferation and the synthesis of collagen I.

Conclusions: D1, L0.01, and the combination of D1 and L0.01 induced fibroblast proliferation and increased collagen I synthesis via Erk activation.

Key Words: Actins; Cell Migration Assay; Cell Proliferation; Collagen Type 1; Extracellular Signal-Regulated MAP Kinases; Fibroblast; Glucose; Lidocaine; Muscle, Smooth; Prolotherapy.

\section{INTRODUCTION}

Prolotherapy is a complementary and alternative treat- ment for strengthening the laxative tendon and ligament, and therefore relieves pain by using tissue irritant solutions. Solutions used in prolotherapy are considered to (a) This is an open-access article distributed under the terms of the Creative Commons Attribution Non-Commercial License (http://creativecommons.org/licenses/by-nc/4.0/), which permits unrestricted non-commercial use, distribution, and reproduction in any medium, provided the original work is properly cited.

(C) The Korean Pain Society, 2021
Author contributions: Min Seok Woo: Investigation; Jiyoung Park: Investigation; Seong-Ho Ok: Methodology; Miyeong Park: Investigation; Ju-Tae Sohn: Supervision; Man Seok Cho: Investigation; II-Woo Shin: Supervision; Yeon A Kim: Study conception. 
be inducing cellular osmotic stress or inflammation, thus stimulating the synthesis of growth factors, and beginning the healing process; however, its mechanism is not fully understood [1,2].

Dextrose solution is popularly used in prolotherapy as an irritant solution, and applied in a concentration from $10 \%-25 \%$. Because it is painful during injection, local anesthetics, like lidocaine, are usually treated with dextrose solution. Considering the fact that normal blood glucose concentration is about $100 \mathrm{mg} / \mathrm{dL}(\approx 0.1 \%), 10 \%-25 \%$ is very high concentration. However, there is no in vitro study for evaluating the effects of these concentrations in fibroblasts. The concentration of lidocaine used in prolotherapy is various, dependent on the physician, and usually $0.1 \%-0.5 \%$ is used. However, $0.2 \%$ lidocaine induced cell death of almost all human tenofibroblasts in vitro [3], so these are also relatively high.

The first purpose of our study was to determine which range of concentrations of dextrose solution and lidocaine would be less cytotoxic in fibroblasts. Second, we investigated the molecular mechanism of fibroblast proliferation, which was induced by dextrose and lidocaine through evaluating the extracellular signal-regulated kinase (Erk) pathway activity. Finally, it was to provide information regarding which concentration would be proper for prolotherapy in the clinical field through an in vitro study.

\section{MATERIALS AND METHODS}

\section{Cell culture of NIH-3T3}

The mouse embryonic fibroblast cell line, NIH-3T3, was purchased from the American Type Culture Collection (ATCC, Rockville, MD) and was maintained at $37^{\circ} \mathrm{C}$ with $5 \% \mathrm{CO}_{2}$ in an air atmosphere; the cells were grown in Dulbecco's Modified Eagle's Medium (DMEM) high glucose (glucose $4,500 \mathrm{mg} / \mathrm{L}, 0.45 \%$ ) supplemented with $10 \%$ bovine calf serum.

\section{Materials}

The following reagents were obtained commercially: Polyclonal rabbit anti-Erk $1 / 2$, phospho-Erk $1 / 2$, and RIPA buffer (10x) were purchased from cell Signaling Technology (Danvers, MA); the Polyclonal rabbit anti-collagen I was from Abcam (Cambridge, MA); the DMEM high glucose and bovine calf serum were from Gibco (Gaithersburg, MD); the Monoclonal mouse anti- $\beta$-actin, anti- $\alpha$-smooth muscle actin (SMA), 3-(4,5-dimethylthiazol-2-yl)-2,5-diphenyltetrazolium bromide, thiazolyl blue (MTT), dimethyl sulfoxide (DMSO), trypan blue solutions, and lidocaine hydrochloride monohydrate (L5647-15g) were from Sigma (St. Louis, MO); the Erk inhibitor (PD98059) was from Merck millipore (Bedford, MA); 50\% dextrose solution was purchased from Dai Han Pharm Co., Ltd. (Seoul, Korea). The enhanced chemiluminescence western blotting detection reagents SuperSignal West Pico Chemiluminescent Substrate were from Pierce (Rockford, IL).

\section{Trypan blue exclusion assay}

Cell viability was determined by trypan blue exclusion assay at 24 hours after treating the lidocaine and dextrose solutions. Cells were collected using trypsin-EDTA, stained with $0.2 \%$ trypan blue solution, and counted in a Neubauer's cell counting chamber. The result was related to the number of cells in an untreated control, which was considered $100 \%$.

\section{MTT assay}

NIH-3T3 cells were plated on 96-well plates with 70,000 cells per well, and 6 parallel wells for each condition. On the next day, the medium was replaced with new medium (control medium, medium with $0.01 \%-0.2 \%$ [0.43-8.54 $\mu \mathrm{M}]$ of lidocaine, medium with $0.1 \%-10 \%$ [0.005-0.5 mM] of dextrose, and medium a with mixture of lidocaine and dextrose). The powder of lidocaine and dextrose were treated, and after that it was mixed with media at each weight together. The degrees of proliferation were measured after 24 hours of drug exposure with the MTT. MTT reagent was added to the wells at a final concentration 0.5 $\mathrm{g} / \mathrm{L}$. The cells were allowed to reduce MTT into formazan $\left(4 \mathrm{hr}\right.$ at $\left.37^{\circ} \mathrm{C}\right)$, the amount of which was measured spectrophotometrically at a wavelength of $560 \mathrm{~nm}$ against the background (650 $\mathrm{nm})$ after lysing the cells in DMSO.

\section{Migration assay}

NIH-3T3 cells were seeded into the Culture-Insert 2 well (ibidi GmbH, Gräfelfing, Germany). Cells were incubated for 24 hours and separated from the Culture-Inserts. Closure of the resulting wound was monitored over the next 24 hours. Images of the wound were captured at different time points using a Nikon eclipse Ti-S inverted microscope (Nikon Instruments Inc., Tokyo, Japan). The cell-free area was measured using ImageJ densitometry software (National Institutes of Health, Bethesda, MD).

\section{Western blot analysis}

The cells $\left(2 \times 10^{6}\right)$ were washed twice with ice-cold phosphate buffered saline, suspended in $100 \mu \mathrm{L}$ of ice-cold RIPA 
buffer (1×) (20 mM Tris-HCl, $150 \mathrm{mM} \mathrm{NaCl}, 1 \mathrm{mM} \mathrm{Na}{ }_{2} \mathrm{ED}$ TA, 1 mM EGTA, 1\% NP-40, $1 \%$ sodium deoxycholate, 2.5 mM sodium pyrophosphate, $1 \mathrm{mM} \beta$-glycerophosphate, 1 $\mathrm{mM} \mathrm{Na}_{3} \mathrm{VO}_{4}, 1 \mu \mathrm{g} / \mathrm{mL}$ leupeptin, and $1 \mathrm{mM}$ phenylmethylsulfonyl fluoride), and incubated at $4^{\circ} \mathrm{C}$ for 30 minutes. The lysates were centrifuged at $14,000 \mathrm{rpm}$ for 30 minutes at $4^{\circ} \mathrm{C}$. Protein concentrations of the cell lysates were determined using a Bradford protein assay reagent (Bio-Rad, Hercules, CA) and $20 \mu \mathrm{g}$ of proteins were loaded onto $7.5 \%$ $15 \%$ sodium dodecyl sulphate-polyacrylamide gel electrophoresis. The gels were transferred to a nitrocellulose membrane (Merk Millipore Ltd., Darmstadt, Germany) and reacted with the indicated antibodies. Immunostaining with antibodies was performed using the SuperSignal West Pico enhanced chemiluminescence substrate and detected using the ChemiDoc Touch Imaging System (BioRad).

\section{Statistical analysis}

At least three independent experiments were conducted. The results are expressed as the means \pm standard deviation. The statistical significance of the differences was primarily determined using the Student $t$-test. $P<0.05$ indicated statistical significance.

\section{RESULTS}

To investigate the effects of the concentration of dextrose and lidocaine used in the clinical field, concentrations from $0.01 \%(0.043 \mathrm{mM})$ to $0.2 \%(0.86 \mathrm{mM})$ of lidocaine, and from $1 \%(5.56 \mathrm{mM})$ to $10 \%(55.6 \mathrm{mM})$ of dextrose, were tested in mouse fibroblasts, NIH-3T3, for 24 hours. More than $0.1 \%$ of lidocaine and $5 \%$ of dextrose decreased cell viability, and cells exposed to $0.2 \%$ of lidocaine and $10 \%$ of dextrose almost died (Fig. 1). Examining the cells with
A

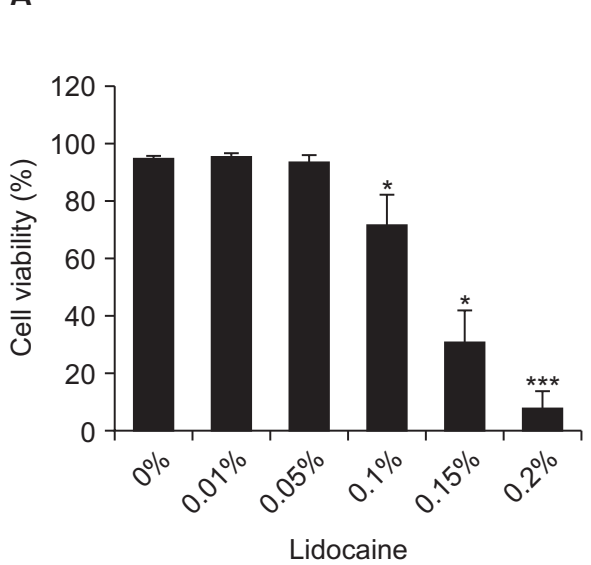

C

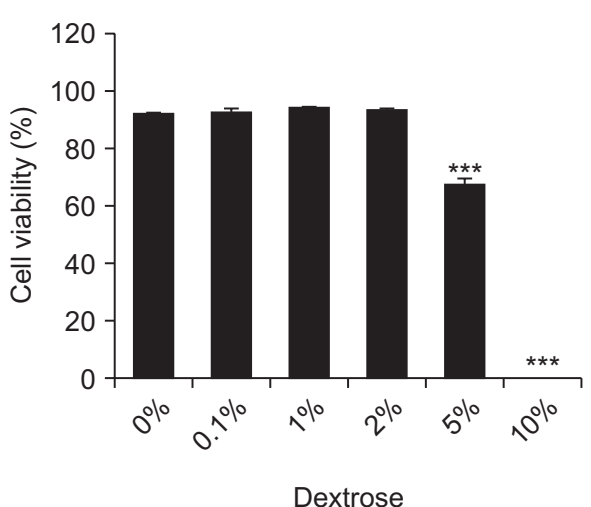

B

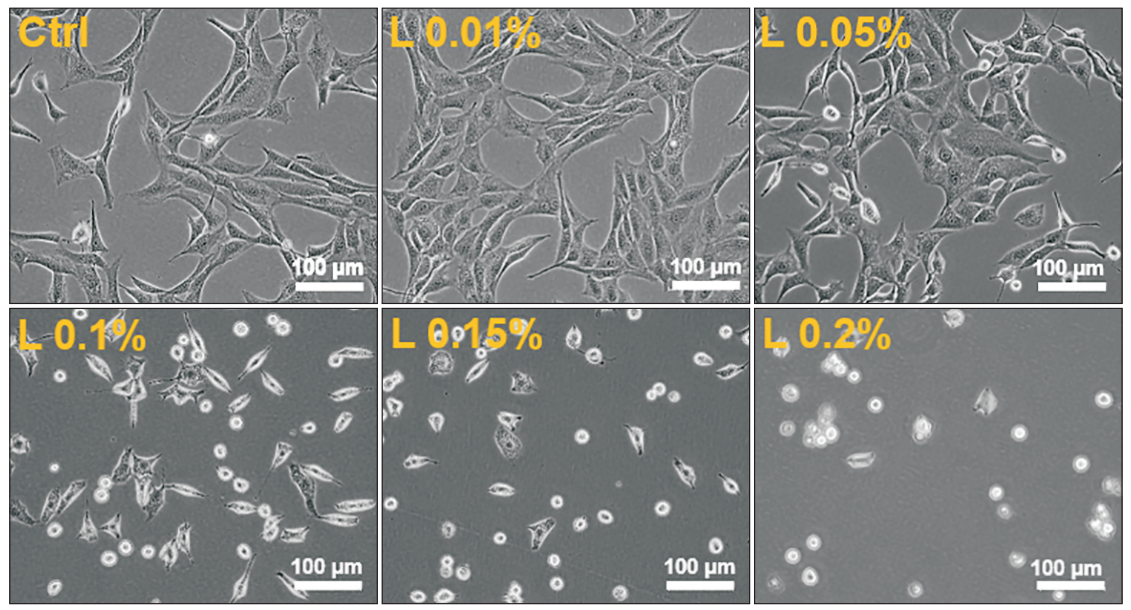

D

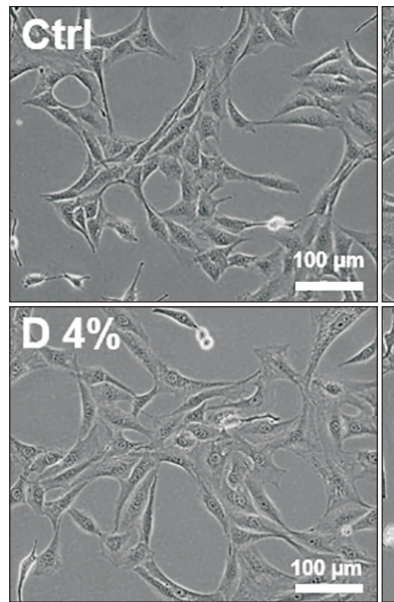

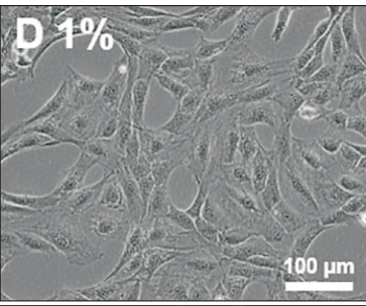
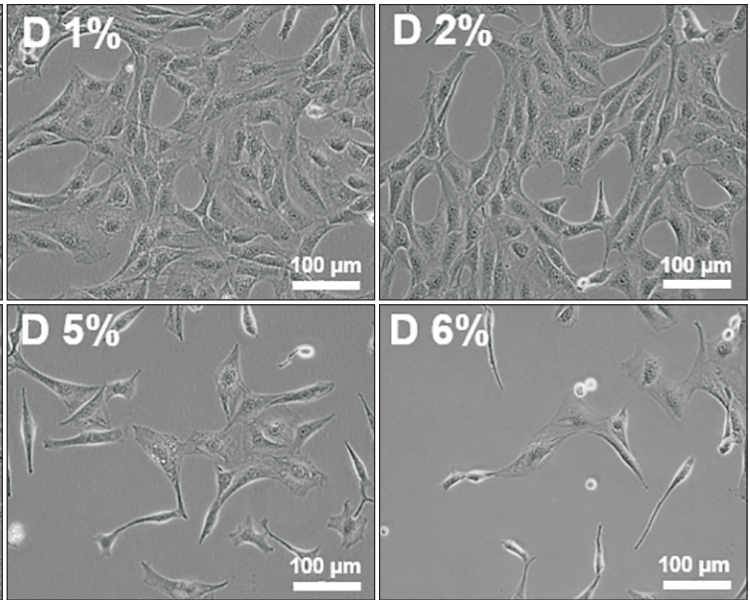

Fig. 1. Trypan blue exclusion assay after treating the various concentrations of lidocaine and dextrose for 24 hours in NIH-3T3. Cell viability after treating various concentrations of lidocaine (A), and dextrose $(C)$, and inverted microscopic images, respectively (B: lidocaine, D: dextrose). Medians and standard deviation, $\mathrm{n}=8$ for each group. Ctrl: control. ${ }^{*} P<0.05$ and $* * * P<0.001$. 

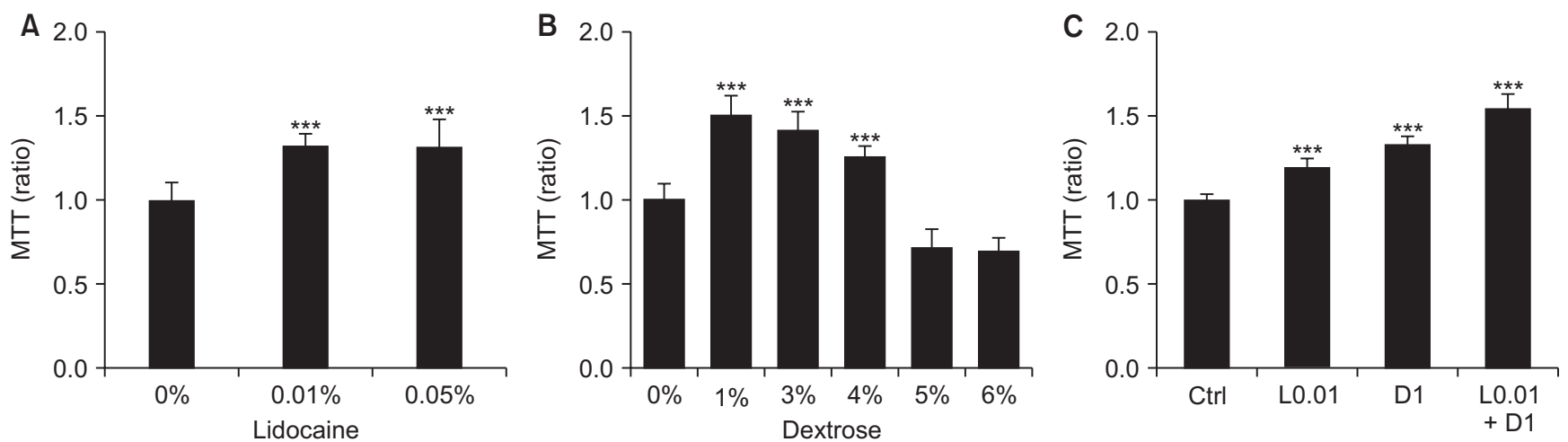

Fig. 2. 3-(4,5-dimethylthiazol-2-yl)-2,5-diphenyl tetrazolium bromide (MTT) assay after treating $0.01 \%$ and $0.05 \%$ of lidocaine (A), dextrose (B), and 0.01\% of lidocaine (L0.01) and 1\% of dextrose (D1) and combination treatment of L0.01 + D1 (C) for 24 hours. Medians and standard deviation, $n=8$ for each group. Ctrl: control. ***P<0.001.

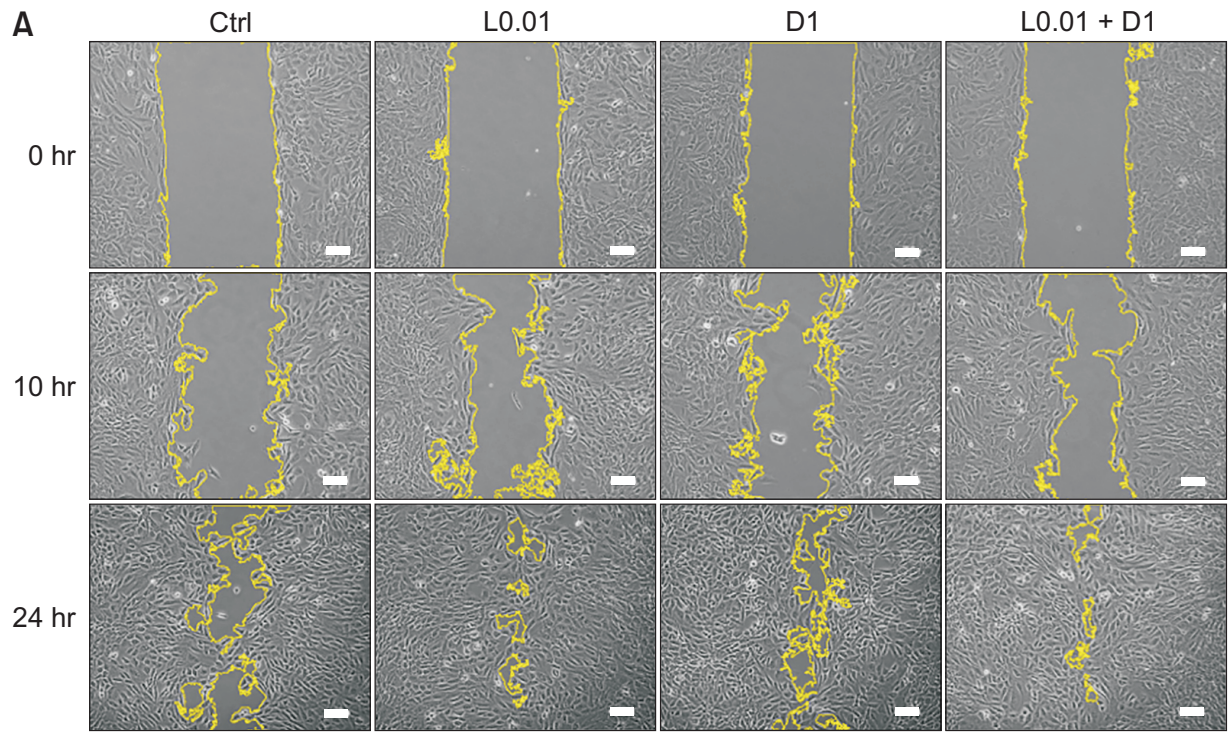

B

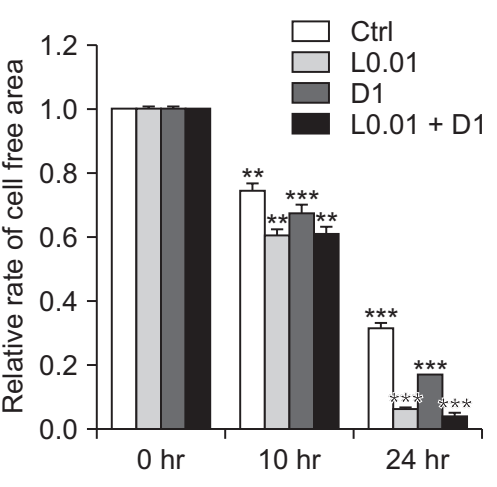

Fig. 3. Lidocaine and dextrose increase the motile activity of fibroblast. Migration assay after treating L0.01, D1, and L0.01 + D1 for up to 24 hours. (A) Inverted microscopic image for quantifying the cell free area (scale bar $=100 \mu \mathrm{m}$ ), and (B) quantified data for cell free area using the Image J. Medians and standard deviation, $\mathrm{n}=3$ for each group. Ctrl: control. $* * P<0.01$ and $* * * P<0.001$.

an inverted microscope, we found that $0.01 \%-0.05 \%$ of lidocaine and $1 \%-3 \%$ of dextrose appeared to mildly induce the proliferation of fibroblasts (Fig. 1B, D), therefore MTT assay was performed. The results were similar with microscopic observation. The concentrations in $0.01 \%$ and $0.05 \%$ of lidocaine and 1,3 , and $4 \%$ of dextrose increased the cell numbers (Fig. 2A, B). Because lidocaine and dextrose are usually combined in prolotherapy, we treated with them concurrently in the fibroblasts and there was no negative effect (Fig. 2C).

Motile activity, which is an important factor for wound healing, was also increased in $0.01 \%$ of lidocaine (L0.01) $1 \%$, and of dextrose (D1), combined treatment of L0.01 and D1 was further increased the cell motility (Fig. 3).

L0.01, D1, and L0.01 + D1 increased Erk activation (Fig. 4A-C) and collagen I synthesis (Fig. 4D, E), and one of the markers of differentiation from fibroblast to myofibroblast, $\alpha$-SMA expression, also increased (Fig. 4D, F). Fibroblast proliferation and collagen I synthesis were suppressed by Erk activation inhibition (Fig. 5).

\section{DISCUSSION}

This study demonstrated that relatively lower concentrations of lidocaine and dextrose, compared with concentrations used in clinical practice, induced fibroblast proliferation and increased collagen I synthesis via Erk activation. The basic concept of prolotherapy is the regeneration and repair of tissue through initiating the wound healing process by inducing inflammation using irritants [1]. However, we suggest a low concentration of dextrose solution 
A

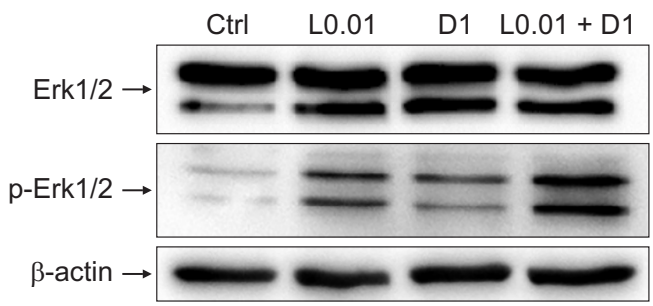

D

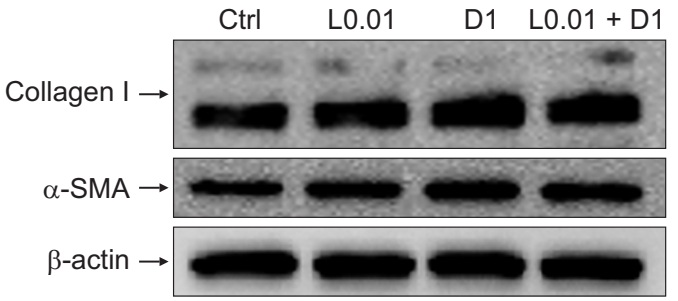

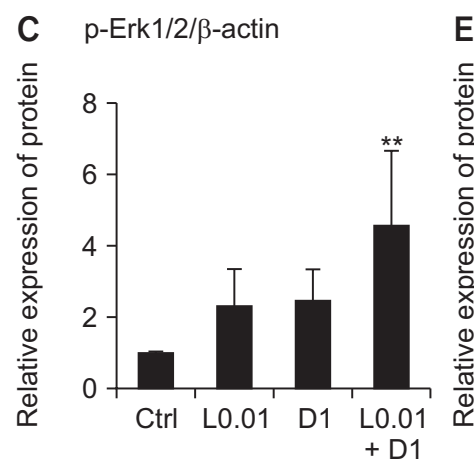
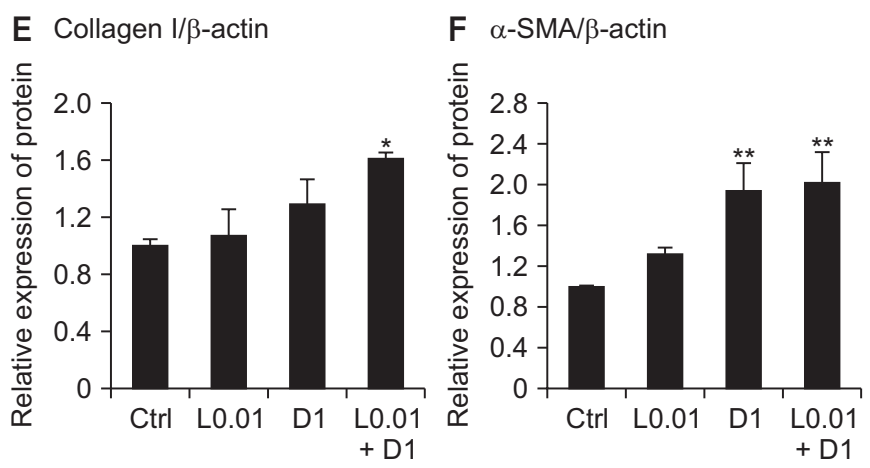

Fig. 4. Lidocaine and dextrose activate the extracellular signal-regulated kinase (Erk) signaling pathway and increase the collagen I and $\alpha$-smooth muscle actin ( $\alpha$-SMA) synthesis. Representative data of western blotting for Erk1/2 and phospho-Erk1/2 (p-Erk1/2) after treating L0.01, D1, and L0.01 + D1 during 3 hours (A), relative expression level of Erk1/2 for $\beta$-actin (B), relative expression level of $p$-Erk1/2 for $\beta$-actin (C), representative data of western blotting for collagen I and $\alpha$-SMA during 24 hours (D), relative expression level of collagen I for $\beta$-actin (E), and relative expression level of $\alpha$-SMA for $\beta$-actin (F). Medians and standard deviation, $\mathrm{n}=3$ for each group. Ctrl: control. $* P<0.05$ and $* * P<0.01$.

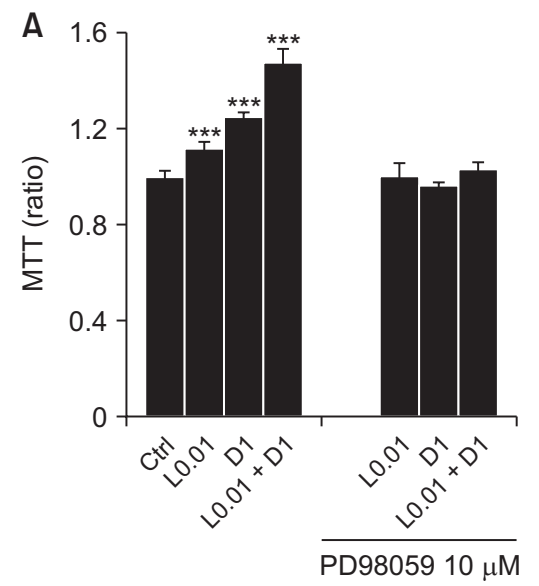

B

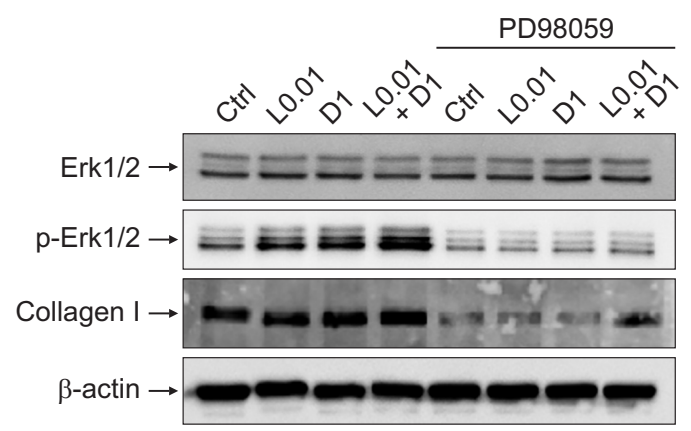

Fig. 5. Inhibition of extracellular signal-regulated kinase (Erk) phosphorylation suppresses the fibroblast proliferation and collagen I synthesis. (A) 3-(4,5-dimethylthiazol-2-yl)-2,5-diphenyl tetrazolium bromide (MTT) assay after treating L0.01, D1, and L0.01 + D1 with Erk inhibitor (PD98059; $5 \mu$ M and $10 \mu \mathrm{M}$ ) for 24 hours, $n=7$. (B) Representative data of western blotting for Erk1/2, phospho-Erk1/2 ( $p$-Erk1/2), and collagen I expression after treating L0.01, D1, and L0.01 + D1 with PD98059 $10 \mu \mathrm{M}$ during 3 hours, $\mathrm{n}=3$. Medians and standard deviation. Ctrl: control. $* * * P<0.001$.

which is not expected to induce excessive inflammation, and can contribute the matrix formation of tissue.

Since the prolotherapy technique has been applied, several irritant solutions have been used, i.e., phenol, glycerin, morrhuate sodium, and high concentration of dextrose solution [4]. One of them, dextrose solution, has been used very popularly and safely. In clinical settings and studies, various concentration of dextrose from $10 \%$ to $25 \%$ with lidocaine from $0.075 \%$ to $1 \%$ have been used [5-7]. However, there has been no in vitro, in vivo study to determine which concentration of dextrose is effective for the proliferation of fibroblasts and regeneration of tendons and ligaments. There have only been guesses from studies performed under diabetic or high glucose conditions with other cell lines. In many studies for diabetic condition-mimicking experiments, the range of high glucose concentration was from $0.5 \%$ to $1 \%$ and these induced proliferation in mesangial cells [8], retinal astrocytes [9], vascular smooth muscle cells [10], endometrial cancer cells [11], and cholangiocarcinoma cells [12], whereas they 
induced apoptosis or cell dysfunction in endothelial cells $[13,14]$, stem cells [15] and schwann cells [16]. As the normal extracellular glucose concentration is considered to be $0.1 \%$, more than $10 \%$ dextrose is very high. DMEM high glucose, used in present study, contains the $4,500 \mathrm{mg} / \mathrm{L}$ of glucose, i.e., $0.45 \%$, therefore, $1 \%$ of dextrose (D1) means $1.45 \%$ of glucose in total. Therefore, the concentration of dextrose solution considered for clinical use in prolotherapy should be $10 \%-25 \%$. If a lower concentration of dextrose could induce enough fibroblast proliferation and myofibroblast differentiation for matrix formation, it might be less painful, and decreases in the lidocaine concentration or volume would induce less inflammation, and reduce the recovery time.

Lidocaine is commonly used in prolotherapy for reliving pain provoked due to the high osmolality of dextrose. It is known that lidocaine induces apoptotic cell death of various types of cells [17-21]. Sung et al. [3] reported there were few live human tenofibroblasts left in $1 \%$ lidocaine treatment. Onizuka et al. [22] also showed that the clinical dose of lidocaine, i.e., more than $5 \mathrm{mM}(\approx 0.17 \%)$ can induce cell death in neurons. Thus, co-treated lidocaine also can affect an adverse effect in fibroblast proliferation or regeneration of tissue. Because $0.2 \%$ of lidocaine induced apoptosis in most studies, the concentration of co-treated lidocaine in prolotherapy should be lower than $0.2 \%$. However, there is a lack of information as to which concentration is sufficient for pain relief while not inducing cell death simultaneously. Our study also shows $0.2 \%$ lidocaine induces the death of almost all fibroblasts at 24 hours after treatment. However, very low concentrations of lidocaine, instead, increased the fibroblast numbers. To our knowledge, this is the first report of a proliferative effect from low concentrations of lidocaine.

The representative pathway of cell proliferation is the Erk pathway [23]. Although the direct mechanism for glucose-induced cell proliferation is not understood, it is well known that glucose-stimulated cell proliferation takes place through the Erk pathway [24,25]. In order to confirm the proliferative effects of $\mathrm{L} 0.01$ and D1, we examined this pathway. Erk was activated distinctly at D1, however, L0.01 also increased phospho-Erk1/2 levels and L $0.01+\mathrm{D} 1$ treatment further elevated it. The inhibition of Erk phosphorylation was also suppressed the proliferative effect of dextrose and lidocaine. It means lidocaine as well as dextrose multiplies the cell numbers through Erk phosphorylation.

It is not certain that increased fibroblast numbers would produce more collagen. In an inflamed condition, fibroblasts differentiate to myofibroblasts and have the increased ability of the extracellular matrix protein synthesis. Differentiated myofibroblasts contain $\alpha$-SMA and it is a characteristic marker of myofibroblasts [26]. It was increased at D1, notably, and it partially explains the increase of collagen I synthesis. In the study of Zhang et al. [27], the inhibition of Erk2 expression effectively prevented epidural fibrosis and collagen synthesis, and Tang et al. [25] reported collagen I and III production from cardiac fibroblasts was dependent on the Erk1/2 phosphorylation. In present study, Erk phosphorylation inhibition suppressed the collagen I synthesis, and high glucose stimulated collagen I synthesis in fibroblasts, also via the Erk pathway.

The migration of fibroblasts or progenitor cells to the injured site is a key step in wound healing. In our study, L0.01 promoted the motile ability of fibroblast much more than D1. The lower concentration of lidocaine and dextrose were also effective in recruiting circumferential fibroblasts. Although there was more than $10 \%$ dextroseinduced cell death in the in vitro culture system, we do not know the response and the role of the in vivo immune system and how the healing process progresses in vivo clearly. According to Sung et al. [3], 0.1\% lidocaine induced cell death during 24 hours in human rotator cuff tenofibroblasts, and this is very similar to our results. Although these results are also from an in vitro system, it is noticeable for using a human live cell culture. Therefore, proliferation in lower concentrations of lidocaine and dextrose is also considered as meaningful. It is necessary to confirm the effects of $1 \%$ dextrose and $0.01 \%$ lidocaine for fibroblast proliferation and collagen I synthesis in an in vivo system. We do not insist that these concentrations are absolute, but only suggest the question; are very high concentrations of dextrose really helpful for prolotherapy? What should also not be missed here is that the cell death was induced by lower concentrations of lidocaine and dextrose, such as $0.2 \%$ and greater than $5 \%$. These concentrations would depend on the species of cells and treatment duration, and the time of absorption after drug injection into the tendon or ligaments of the patient should be considered, because it determines the exposure time of the fibroblasts to the drug. Therefore, it is necessary that well-designed experiments consider these factors.

We examined a simple pathway for fibroblast proliferation and collagen synthesis, however, it is only the first step for evaluating the mechanism of the treatable effects of prolotherapy. We expect prolotherapy to develop into orthodox and conventional medicine, from its current status as complementary and alternative medicine, via the accumulation of knowledge fthrough basic research.

\section{CONFLICT OF INTEREST}

No potential conflict of interest relevant to this article was reported. 


\section{FUNDING}

This study was funded by National Research Foundation of Korea (NRF-2011-0021216).

\section{ORCID}

Min Seok Woo, https://orcid.org/0000-0002-0357-9666 Jiyoung Park, https://orcid.org/0000-0001-5028-2032 Seong-Ho Ok, https://orcid.org/0000-0002-1292-7108 Miyeong Park, https://orcid.org/0000-0002-2632-3014 Ju-Tae Sohn, https://orcid.org/0000-0003-0102-5800 Man Seok Cho, https://orcid.org/0000-0002-6763-2382 Il-Woo Shin, https://orcid.org/0000-0003-1964-4546 Yeon A Kim, https://orcid.org/0000-0003-3364-4307

\section{REFERENCES}

1. Banks AR. A rationale for prolotherapy. J Orthop Med 1991; 13: 54-59.

2. Reeves KD. Prolotherapy: basic science, clinical studies, and technique. In: Pain procedures in clinical practice. 2nd ed. Edited by Lennard TA. Philadelphia, Hanley \& Belfus. 2000, pp 172-90.

3. Sung CM, Hah YS, Kim JS, Nam JB, Kim RJ, Lee SJ, et al. Cytotoxic effects of ropivacaine, bupivacaine, and lidocaine on rotator cuff tenofibroblasts. Am J Sports Med 2014; 42: 288896.

4. Rabago D, Slattengren A, Zgierska A. Prolotherapy in primary care practice. Prim Care 2010; 37: 65-80.

5. Reeves KD, Hassanein KM. Long-term effects of dextrose prolotherapy for anterior cruciate ligament laxity. Altern Ther Health Med 2003; 9: 58-62.

6. Topol GA, Reeves KD, Hassanein KM. Efficacy of dextrose prolotherapy in elite male kicking-sport athletes with chronic groin pain. Arch Phys Med Rehabil 2005; 86: 697-702.

7. Lyftogt J. Subcutaneous prolotherapy treatment of refractory knee, shoulder, and lateral elbow pain. Australas Musculoskelet Med 2007; 12: 110-2.

8. Wang D, Guan MP, Zheng ZJ, Li WQ, Lyv FP, Pang RY, et al. Transcription factor Egrl is involved in high glucose-induced proliferation and fibrosis in rat glomerular mesangial cells. Cell Physiol Biochem 2015; 36: 2093-107.

9. Shin ES, Huang Q, Gurel Z, Sorenson CM, Sheibani N. High glucose alters retinal astrocytes phenotype through increased production of inflammatory cytokines and oxidative stress. PLoS One 2014; 9: e103148.

10. Shi L, Ji Y, Jiang X, Zhou L, Xu Y, Li Y, et al. Liraglutide attenuates high glucose-induced abnormal cell migration, proliferation, and apoptosis of vascular smooth muscle cells by activating the GLP-1 receptor, and inhibiting ERK1/2 and PI3K/Akt signaling pathways. Cardiovasc Diabetol 2015; 14: 18.

11. Han J, Zhang L, Guo H, Wysham WZ, Roque DR, Willson AK, et al. Glucose promotes cell proliferation, glucose uptake and invasion in endometrial cancer cells via AMPK/mTOR/ S6 and MAPK signaling. Gynecol Oncol 2015; 138: 668-75.

12. Saengboonmee C, Seubwai W, Pairojkul C, Wongkham S. High glucose enhances progression of cholangiocarcinoma cells via STAT3 activation. Sci Rep 2016; 6: 18995.

13. Wang R, Lu L, Guo Y, Lin F, Chen H, Chen W, et al. Effect of glucagon-like peptide-1 on high-glucose-induced oxidative stress and cell apoptosis in human endothelial cells and its underlying mechanism. J Cardiovasc Pharmacol 2015; 66: 135-40.

14. Tsai HY, Lin CP, Huang PH, Li SY, Chen JS, Lin FY, et al. Coenzyme Q10 attenuates high glucose-induced endothelial progenitor cell dysfunction through AMP-activated protein kinase pathways. J Diabetes Res 2016; 2016: 6384759.

15. Cheng NC, Hsieh TY, Lai HS, Young TH. High glucoseinduced reactive oxygen species generation promotes stemness in human adipose-derived stem cells. Cytotherapy 2016; 18: $371-83$

16. Qu L, Liang X, Gu B, Liu W. Quercetin alleviates high glucose-induced Schwann cell damage by autophagy. Neural Regen Res 2014; 9: 1195-203.

17. Lee HT, Xu H, Siegel CD, Krichevsky IE. Local anesthetics induce human renal cell apoptosis. Am J Nephrol 2003; 23: 129-39.

18. Kamiya Y, Ohta K, Kaneko Y. Lidocaine-induced apoptosis and necrosis in U937 cells depending on its dosage. Biomed Res 2005; 26: 231-9.

19. Grishko V, Xu M, Wilson G, Pearsall AW 4th. Apoptosis and mitochondrial dysfunction in human chondrocytes following exposure to lidocaine, bupivacaine, and ropivacaine. J Bone Joint Surg Am 2010; 92: 609-18.

20. Chang YC, Hsu YC, Liu CL, Huang SY, Hu MC, Cheng SP. Local anesthetics induce apoptosis in human thyroid cancer cells through the mitogen-activated protein kinase pathway. PLoS One 2014; 9: e89563.

21. Chang YC, Liu CL, Chen MJ, Hsu YW, Chen SN, Lin CH, et al. Local anesthetics induce apoptosis in human breast tumor cells. Anesth Analg 2014; 118: 116-24.

22. Onizuka S, Tamura R, Yonaha T, Oda N, Kawasaki Y, Shirasaka $\mathrm{T}$, et al. Clinical dose of lidocaine destroys the cell membrane and induces both necrosis and apoptosis in an identified Lymnaea neuron. J Anesth 2012; 26: 54-61.

23. Zhang W, Liu HT. MAPK signal pathways in the regulation of cell proliferation in mammalian cells. Cell Res 2002; 12: 9-18.

24. Sugimoto R, Enjoji M, Kohjima M, Tsuruta S, Fukushima M, Iwao $\mathrm{M}$, et al. High glucose stimulates hepatic stellate cells to proliferate and to produce collagen through free radical pro- 
duction and activation of mitogen-activated protein kinase. Liver Int 2005; 25: 1018-26.

25. Tang M, Zhang W, Lin H, Jiang H, Dai H, Zhang Y. High glucose promotes the production of collagen types I and III by cardiac fibroblasts through a pathway dependent on extracellular-signal-regulated kinase 1/2. Mol Cell Biochem 2007; 301: 109-14.

26. Darby IA, Laverdet B, Bonté F, Desmoulière A. Fibroblasts and myofibroblasts in wound healing. Clin Cosmet Investig Dermatol 2014; 7: 301-11.

27. Zhang C, Kong X, Liu C, Liang Z, Zhao H, Tong W, et al. ERK2 small interfering RNAs prevent epidural fibrosis via the efficient inhibition of collagen expression and inflammation in laminectomy rats. Biochem Biophys Res Commun 2014; 444: 395-400. 